\title{
A Case Study: Focusing on Sustainability Themes and Ecocomposition through Student Blogs in a Professional and Technical Writing Course
}

\section{Tara Hembrough}

Assoc. Prof., Southeastern Oklahoma State University, USA, thembrough@se.edu

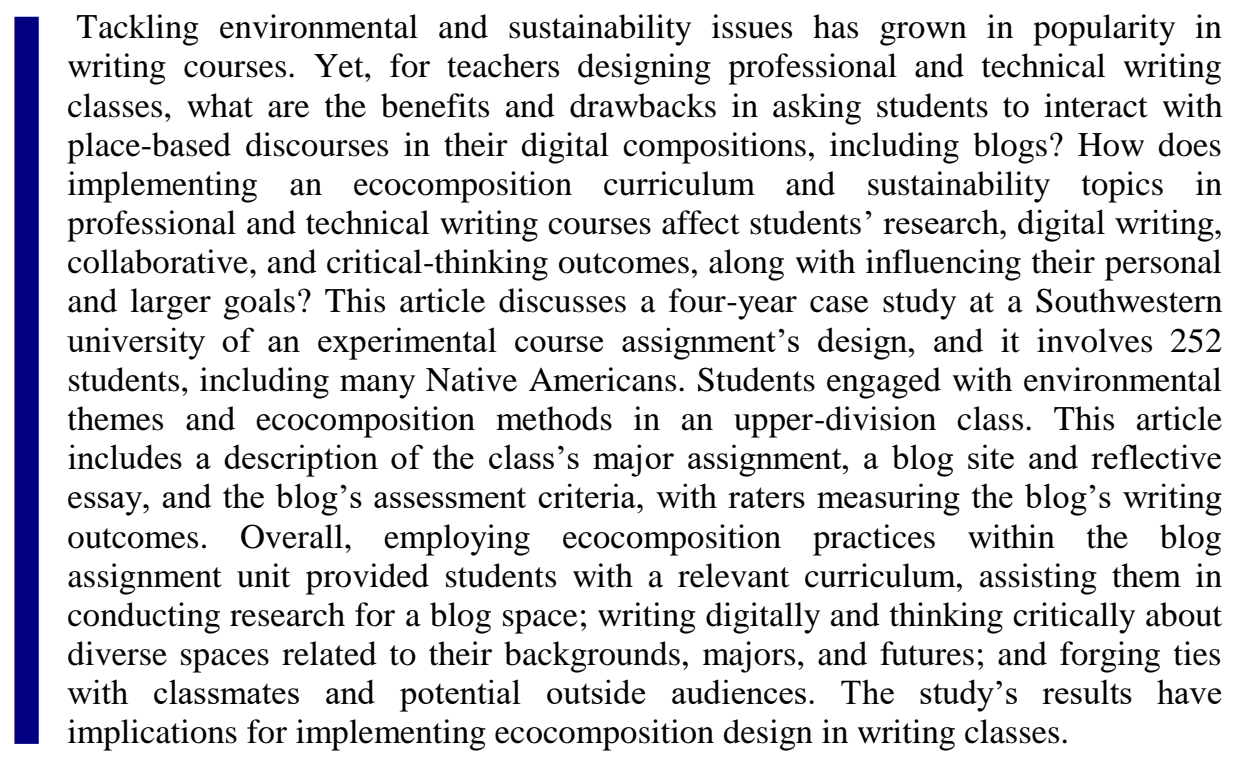

Keywords: professional and technical writing, writing program administration, ecocomposition, environmentally themed composition, place-based composition, blogs

\section{INTRODUCTION}

Ecocomposition represents a recent model for designing the professional and technical writing classroom, as faculty and students investigate environmental topics and contemplate the importance of place for writers navigating the rhetorical situation. Linked to place-related (Sobel, 2004) and progressive education (Dewey, 1915), ecocomposition approaches writing through ecological concepts, including "writing about place" and "writing in place," or "the study of relationships between environments

Citation: Hembrough, T. (2019). A Case Study: Focusing on Sustainability Themes and Ecocomposition through Student Blogs in a Professional and Technical Writing Course. International Journal of Instruction, 12(1), 895-914. https://doi.org/10.29333/iji.2019.12158a 
and discourse" (Dobrin and Weisser, 2002, p. 6). With ecocomposition's "inclusive" stance, students can interact with location-based concerns from feminist, environmental, multicultural, political, and economic lenses, "all by examining matters of form and style, audience and argumentation, and reliable sources and documentation" (Gaard, 2001, p. 163), objectives for many professional and technical writing classes. Utilizing an ecocomposition design, teachers and students can address issues foregrounded within a writing curriculum, as well as interrogate social conflicts located beyond the classroom. Derek Owens (2001) contends that because of a universal set of quickly deteriorating environmental conditions and a rising inequity in resource distribution, writing students should interact with sustainability discourses in the classroom, fashioning the groundwork for "community revitalization" (p. 35). Similarly, drawing upon Paulo Freire, Sidney Dobrin and Christian Weisser argue that students should critique the places they live, attend to local and larger community issues, and contemplate their life's and work's impact (2002b), actions instilling in them a "literacy that is not only practical and political, but ethical" (Brown, 1999, p. 215).

A focus on sustainability, ecology, and climate change has prompted some writing faculty to teach students a greater knowledge of environmental literacy, considering how people and places interact (Long, 2001). Faculty teaching composition classes, such as Owens (2001), as well as professional and technical writing courses, such as Veronica House (2016) and Jimmie Killingsworth (2005), insist that instilling ecocomposition approaches in the classroom represents a necessity for teachers today. Nonetheless, Maureen McKnight (2001) questions whether faculty "need an environmental ethic to legitimate their practices" (p. 928).

In light of instructors' diverging views concerning whether implementing ecocomposition practices is beneficial, should teachers ask students to interact with place-based writing and ecological topics as part of composing a text's rhetorical context? As the basis for this article, this research question motivated a study of ecocomposition approaches and sustainability topics in professional and technical writing course assignment design, with students fashioning a place-related blog. This article involves a four-year case study of an ecocomposition-oriented, Professional and Technical Writing class's blog assignment. The paper explores the class's major assignment, a place-related blog site containing a sustainability component and a coinciding reflective essay on the digital project. The author assessed these assignments in order to identify potential gains in students' writing-related, personal, and larger outcomes. As a teacher, the author formulated the study with the objective of determining whether ecocomposition-designed assignments, including a place-related blog, would strengthen students' depictions of locale as they approached their writing. For the study, the author asked these research questions: How would an ecocompositionconcerned course and a class's sustainability theme impact students', including many Native American students', digital composition of a blog, as well as affecting their ability to engage in research, writing, collaborative, and critical-thinking practices? Would students benefit from the blog assignment's curricular, place-based, interdisciplinary focus, or would the potentially negative consequences of creating a 
blog include students' inability to connect with ecological topics, academically, personally, and in their greater communities?

\section{LITERATURE REVIEW}

Native American College Students and Their Academic Challenges and Learning Styles

Fighting against their ongoing devaluation, Native Americans face intergenerational trauma as a factor affecting their educational outcomes, as well as their general status (Tuhiwai-Smith, 2012). Academically, Native American students battle difficulty in transitioning to college life, locating mentors (Brokenleg, 1990), and aligning their worldviews with institutional norms situated in course pedagogy and philosophy (Hankes, 2002). On campus, Native students may experience feelings of academic inadequacy, alienation, and marginalization (Guillory, 2009; Guillory \& Wolverton, 2008). Likewise, often, the curricula fails to meet Indigenous students' requisites and acknowledge their worldviews and native knowledge (Curnow, 2011; Munroe et al., 2013; Smith \& Sobel, 2010). Consequently, Native American students desire involved teachers, a curricula that projects an awareness of Native identity (Conley \& Bryan, 2009), and a university that respects their culture, background, and community (Mosholder, 2016). In instructing Native American students, teachers should be culturally literate concerning students' backgrounds, self-reflective about their own worldviews, caring and inclusive, and respecting of diversity as they assist students in becoming citizens who value their communities (Pewewardy \& Cahape-Hammer, 2003). Additionally, instructors must fashion an environment for Native American students' cultural expression (Bowman, 2018; Guillory, 2008; Yazzie, 2000), as well as assisting students in strengthening their ethnic identities (Huffman, 2001).

Overall, to succeed, Indigenous students require student-centered practices (Deloria \& Wildcat, 2001), customized learning approaches, and a community of learners' aid (Bowman, 2018; Conley \& Bryan, 2009; Lipka, 2002), since they enjoy group-learning approaches (Larimore, 2000) and engaging with and instructing others (Conley \& Bryan, 2009). Moreover, some Native American students need academic assistance, especially in the areas of English and writing (Guillory, 2008). When Native students feel confident about their academic skills and backgrounds, they do better in college (2008). Indeed, in one study, an Indigenous teacher increased her course's learning outcomes by utilizing a curriculum featuring oral storytelling, pictorial, and creative writing elements; implementing a culturally appropriate approach; and foregrounding a place-based curriculum concentrated on students' lives and communities (Sianturi, Chiang, \& Au Hurit, 2018).

Finally, many Native American students wish to be involved with nature as part of their learning environment, a factor aligning with Howard Gardner's Multiple Intelligences' category of demonstrating naturalistic intelligence (Conley \& Bryan, 2009). While Western science values the practices of observation and experimentation, Native science calls upon one's use of observation and lived experience (Bahr, 2015; Hain-Jamall, 2013). Since Native American culture values balance, reciprocity, and a holistic view of systems, Native Americans consider how nature will be affected in the decisions they 
make (Hain-Jamall, 2013). Developing a relationship with the environment, participating in a tribal-centered community, and concentrating on nature allow Native Americans to identify their character and vocation, assisting them in the expression of a complete life (Pewewardy \& Cahape-Hammer, 2003). Moreover, most Native Americans are conservation minded (Aftandilian, 2011), even though, within this discussion, it is important not to stereotype Indigenous worldviews and cultures, as, often, Anglo visions of Native Americans cast them as being environmental caretakers (Aftandilian, 2011; Harkin \& Lewis, 2007; Porter, 2012).

\section{Environmentally Themed Courses and Ecocomposition Design Approaches}

In terms of course themes and writing classroom design, some teachers have offered nature-oriented topics and place-based writing practices. To promote an awareness of sustainability in composition students, teachers have concentrated on interdisciplinary, environmental subjects and energy practices (see Goggin \& Waggoner, 2005; Heiman, 2014; Long, 2001; Owens, 2001), discussed nature themes (Johnson-Sheehan, 2007), and implemented ecocomposition approaches (Beaufort, 2012; Dobrin \& Weisser, 2002; Hothem, 2009; Merrill-Ingram, 2001; Walker, 2010). When educators make environmental literacy "visible and relevant enough" to interest students, the latter may link class subjects to their personal backgrounds and careers (Goggin \& Waggoner, 2005) and understand how environmentalism is addressed in various discourse communities (Beaufort, 2012).

For many of the compositionists discussed here, the objective of building students' ecological literacy by exploring social, economic, and scientific environmental viewpoints is not simply to address writing goals, but also to raise issues, find solutions, and prompt individual and communal change. Possessing scientific literacy, too, is an important criterion in an era of increasing technology, and establishing environmentally oriented classes can aid students in comprehending how science impacts the culture at large and how discourse is fashioned (Heiman, 2014; Hothem, 2009). Overall, ecocomposition allows students to address audience concerns; work collaboratively with local groups; reflect upon coursework (Goggin \& Waggoner, 2005); connect to natural areas (Johnson-Sheehan, 2016); and learn about ecological issues at introductory stages, thus raising students' confidence levels, communication capabilities, and peer review and revision skills (Merrill-Ingram, 2001). Likewise, ecocomposition designs create an environment in which students identify writing assignments as being more genuine, as opposed to simulated (Monsma, 2001).

Universities can be change agents for sustainability, including through teachers' positioning of the curriculum and offering of mutual learning practices involving both students and the greater society in their addressing of specific environmental challenges (Stephens et al., 2008). By presenting current topics, including place-related ones, to interest students and develop their writing skills, faculty can facilitate students' deeper learning processes and analytical abilities (Friedman, 2013; Heiman, 2014). Furthermore, most college students have inward-centered views (Graff \& Hoberek, 1999), so teachers of general education courses must introduce critical-thinking practices (Szostak, 2003; Weed, 2003). Yet, for students to feel inspired by themed 
class material, the curriculum must be relevant and challenging also (Bovill, Bulley, \& Morss, 2011). In one study concerning the writing classroom, students expressed that having the opportunity to compose work about important issues to them was the largest element in their experiencing of successful outcomes. Nevertheless, students must identify with class themes both individually and generally to become better writers (Sommers \& Saltz, 2004).

In response to the inclusion of environmental themes in their courses, some teachers have observed conflicts, however. Donovan McFarlane and Agueda Ogazon argue that the culture has a narrow comprehension of sustainability discussions (2011), as "sustainability" is "a plastic but potent signifier" (Alaimo, 2010, p. 558). For example, the abstract nature of environmentally- and economically-based sustainability terms may present issues for conflicting parties hoping to discover solutions to issues amenable to all (Walker, 2010). Like the term "sustainability," "nature" also represents a contrived concept, but Mark Long (2001) contends that teachers can offer students ecocritical perspectives nonetheless. Still, as David Orr (1990) found in his class about exploring campus environments, some students remain unaffected by resource-related questions, regardless of teacher strategy.

A separate issue with offering place-based themes, more generally, is that some students, remembering high school, possess different perceptions of what writing classes should entail than do faculty. In James Heiman's (2014) case, students believed that his composition class seemed more like a philosophy or science one, and in a survey, 75 percent identified literary topics as being the only acceptable ones for a writing course. Additionally, Heiman's students demonstrated a disdain for "unfamiliar [reading] content," writing topics not self-selected, and the absence of "creative" writing assignments (2014, p. 111). Overall, Heiman discovered that persuading students to view science as being an "appropriate," "interesting and applicable" course subject represented a problem in his class (2014). Indeed, composition instructors may need to identify the value, for students, of covering environmental themes, as in high school, many teachers focus on expressive writing (Fitts, 2005). Likewise, faculty should offer students the chance to formulate their own personal responses to the landscape (Gaard, 2001; Killingsworth, 2005; Marx, 2008). For instance, when Thomas Hothem (2009) presented scientific theories as being relevant examples in a "Suburban Studies" writing class, his students failed to make the connection. Hothem found success only upon linking the discussions to students' lives.

As a major finding connected to the ecocomposition studies reviewed here, upon conducting a study involving a sustainability-themed, writing classroom, Goggin and Waggoner (2005) identified that students gained a greater understanding of both sustainability concepts and writing discussions. Furthermore, the caliber of the students' written report, as an important course assignment, was rated higher than average. Nonetheless, neither Goggin and Waggoner nor the other authors reviewed previously formally assessed student work as a measurement for their studies. Likewise, some scholars offer best practices for teachers implementing course themes, yet none have presented large-scale, writing-course prototypes centering on sustainability subjects or 
ecocomposition concepts, especially in professional and technical writing classes. Additionally, as a separate concern, it is crucial that college administrators and teachers understand what aids Native American students in finishing their college education (Guillory, 2009), including completing their writing courses.

Thus, the significance of this article is that it discusses the author's Professional and Technical Writing course blog assignment, which foregrounds an ecocomposition design, as an unexplored curricular model. The author's purpose in conducting the study was to understand how the blog assignment might improve students' composition and other outcomes. This study, located, at a public, Southwestern regional university, involved 252 students, including many Native Americans. Taking into account scholars' dialogues about assisting students in depicting important places and identifying sustainable futures for themselves as part of their writing tasks, the author discusses how a professional and technical writing class's blog assignment was approached to meet intermediate writers' needs. Investigating the sustainability-themed blog assignment as a curricular model that might illuminate larger patterns of interest, based upon the study's research questions, the author considers how the assignment impacted students' engagement with environmental topics and how the outcomes could be measured. This article offers ways to promote students' investment in an ecocomposition classroom through a blog assignment, as well as encouraging students to interact with their communities along ethical and tenable lines. Overall, findings indicate that the blog assignment benefitted many students' digital writing, research, collaborative, and critical-thinking practices, as well as impacting their personal practices and career goals.

\section{METHOD}

\section{Purpose}

Having IRB approval, the author designed the study as an exploratory case study (Cresswell, 2012). An exploratory case study offers an "opportunity to learn" (Stake, 1995 , p. 6), and the author wanted to understand students' values concerning both their writing and sustainability practices, as well as their ties to place (see Baskarada, 2014). Through a case study, one can analyze a programmatic design holistically and fully to generate a comprehension of it and its relation to participants, and to describe the case (Baxter \& Jack, 2008). Concerning the study's aims or purpose, the author investigated how an ecocomposition course focus and sustainability themes, as expressed in the major assignment, a blog, would affect students' digital composing habits, as well as connect to their personal interests and majors. Additionally, the author considered how the blog assignment and reflective essay might be assessed to measure writing outcomes.

\section{Research Site and Curriculum}

From 2015 through 2018, the author conducted the study at a Southwestern, regional, public university, serving the state's lowest income county. The town where the university is situated represents one tribe's capital, but the college itself lays outside of tribal nation jurisdiction. Also pertinent to the institution's background, the historical removal of Indigenous groups to Indian Territory (predominantly the state of Oklahoma) has impacted negatively many Native Americans' native languages and cultural features (Dippel, 2014), a situation that arguably precipitates the need for students, desiring to do 
so, to describe places of importance to them. In 2018, the university's undergraduate enrollment represented 3,200 students, mostly state residents. Many undergraduates possess low-income backgrounds, 57 percent are first-generation college students, and 30 percent are registered as Native American, mostly Choctaw and Chickasaw ("Factbook," 2018). The freshmen retention rate represents 64 percent, below the national average of 72 percent. Moreover, only a little over 11 percent of students graduate within six years, and 28 percent finish at all. According to prospects at similar institutions, students should be graduating at a rate of over 39 percent (2018). Thus, at this locale, like elsewhere, some students face persistence issues, and it is vital for teachers to fashion assignments, including writing tasks, matching students' needs and values. Comparably, nationally, within six years, the overall Native American graduation rate is only 36 percent, compared with 56 percent in the general student population (Shotton, Oosahwe, \& Cintron, 2007).

To fulfill degree requirements, many students, including those majoring in business, take Professional and Technical Writing, a class in which they learn to communicate ideas, assist people in using products and performing tasks, report results, persuade readers of the desirability of a course of action, document decisions, and facilitate various tasks. Of the units, the blog site represents the major one. To orchestrate a space for ecocomposition, the author asked students to interact with sustainability conversations by generating a blog about a significant place to them, one that offered some natural component, and to address the environmental concerns there. To begin the unit, students read course selections about deforestation, climate change, sustainable practices, water conservation, and organic farming. Then, to design the blog, students examined their personal relationships to their places and described times in which they visited them and the activities in which they had engaged. Next, to foster critical thinking, students read about environmental approaches relevant to their location. Moreover, students delineated their blog's target audience, usually out-of-state visitors. Overall, students created a blog including both printed textual and multimodal elements, such as pictures, maps, or links. Afterwards, they composed a reflective essay examining their blog's significance, including the need for their place's protection as a historical or natural space. As in Owens's (2001) classroom, the blog assignment began with students' emphasis on the "personal, local and familiar" and became "more abstract, global" (p. 217), as students discussed their experiences with a location and identified ways to sustain it. As examples of foci upon a place's natural, cultural, and spiritual significance, one Choctaw student wrote about the nearby Spiro Mounds Archeological Center.

\section{Research Methods}

A case study involves collecting data from multiple sources to formulate a case description and themes (Cresswell, 2012), and the author utilized diverse data collection instruments to generate results (see Yin, 2009), including pre- and post-surveys, each having a total of 25 Likert-style and open-ended questions; students' blog and reflective essay assignments; and university and local webpages about services and programs related to sustainability topics. Via the online surveys as the first data collection instrument, students revealed information about their 1) engagement with reading, 
writing, and thinking about sustainability course topics, as well as their participation in collaborative, class activities; 2) involvement in sustainable activities; and 3) personal, educational, and career goals and demographic backgrounds. Likewise, as the second data collection instrument, the author and another writing researcher evaluated 100 students' blogs and reflective essays for references to students' sustainability and placerelated views. Out of the participants' total number, the author chose this smaller sample at random. In filing data, the author gave participants pseudonyms and kept the list of pseudonyms and associated names in a password-encrypted file.

To provide for flexibility and adaptation, the study applied a constructivist grounded theory methodology to collect data and formulate themes in the data linked to the research questions as an analysis technique (Strauss, 1987). To explore the study's common strands, the author and other researcher analysed the data via these steps: reading and annotating the documents; locating themes; generating a coding scheme, which entails listing the themes and codes to be applied; and coding the data (Bricki \& Green, 2007) by writing codes in the documents' margins. Additionally, on the computer, the author made distinct files for each code by cutting and pasting information, and placing all information for a participant in its own file to maintain distinct pictures or narratives of people and events (2007). The codes utilized were linked to the author's research questions, allowing for the identification of preliminary themes and study outcomes. With this process, the author and other researcher coded all data to create internal consistency. The correlation coefficients used to assess inter-rater reliability within this dataset ranged from good to adequate in all areas. Finally, relying on existing literature concerning the subject, and the themes determined during the study, the author utilized an analytical framework to connect the data and build a storyline (Yin, 2009) about the study's setting, participants, and chronology to generate a description of the case's details (Cresswell, 2012), as linked to the author's general research question concerning whether students would enjoy and benefit from building a place-based blog. An analytical framework suggests that data from all participants, with their varying viewpoints, may be important (Strand et al., 2003).

Next, as the third data collection instrument, the author orchestrated a rubric to calculate writing outcomes for the blog and chose 50 students' blogs randomly to critique their work. The author selected this assignment for assessment because in engaging it, students discussed their experience with a certain place, as well as analyzing texts related to its sustainability, and so it represented a measure of their interaction with environmental discourses. Acting as raters, the author and other writing researcher compared students' work. On a five-point scale, raters rated each blog's organization; development and clarification of ideas; diction, style, and voice; and audience and genre features, including the addressing of assignment guidelines. Inter-rater reliability coefficients indicated that the raters correlated perceptions of students' achievement in the blog's development and clarification of ideas, and organization most closely. Interrater reliability coefficients are as follows: 1) development and clarity $(.864 \%) ; 2$ ) organization $(.775 \%) ; 3)$ diction, style, and voice $(.596 \%)$; and 4 ) audience and genre requirements $(.596 \%)$. Correlation coefficients used to assess inter-rater reliability within this dataset ranged from good to adequate in all areas. 
To offer credibility to the study's claims, the author was immersed in prolonged field engagement (2012), contemplating the research questions over a long period, and also offered thick descriptions of some students' backgrounds to foster a sense of reality for readers (Cresswell \& Miller, 2000). Additionally, the author utilized the process of data triangulation by implementing "multiple sources of data" and "multiple methods to confirm the [study's] emerging findings" (Merriam, 1985, p. 204). Furthermore, by selecting an exploratory case study; utilizing both surveys and artifacts, including student papers; and employing a constructivist grounded theory, the author followed the protocols of other researchers reviewed to ensure that the research design was appropriate and the methodology consistent with the practice. The data collection instruments were constructed based on theories from Goggin's and Waggoner's study (2005), reviewed previously.

\section{Sample Demographics}

In the study, the 252 participants ranged in age from 17 to 56 , with the majority being in their early twenties. While enrolled at the university, there is a greater balance between the sexes, in the study, males represented 32.8 percent and females 67.2 percent of participants. Additionally, Caucasian students represented the majority, with Native Americans ranking second. Moreover, 48 percent of students had a combined household income of below $\$ 30,000$, thus living at the poverty level. Students from many disciplines participated. Refer to Table 1 for group demographics.

Table 1

Students' Demographic Characteristics

\begin{tabular}{ll}
\hline Race & Caucasian $=70 \%(n=176) ;$ Native American $=21 \%(n=53) ;$ Hispanic/Latino \\
& $=4 \%(n=10) ;$ African-American $=3 \%(n=8) ;$ Asian/Pacific Islander $=2 \%(n=5)$ \\
\hline Age & $17=>1 \%(n=3) ; 18-21=55 \%(n=139) ; 22-25=37 \%(n=94) ; 26-29=>1$ \\
& $\%(n=1) ; 30-34=>1 \%(n=3) ; 35-39=>1 \%(n=3) ; 40-44=>1 \%(n=3) ; 45-$ \\
& $49=>1 \%(n=3) ; 50-54=>1 \%(n=2) ; 55-59=>1 \%(n=1)$ \\
\hline Income & $\$ 0-15,000=14 \%(n=35) ; \$ 16,000-30,000=23 \%(n=58) ; \$ 31,000-45,000=$ \\
& $19 \%(n=48) ; \$ 46,000-60,000=19 \%(n=48) ;>\$ 60,000=25 \%(n=63)$ \\
\hline Degree & Business $=49 \%(n=125) ;$ Arts and Humanities $=16 \%(n=41) ;$ Arts and \\
Program & Sciences $=5 \%(n=13) ;$ STEM Sciences $=31 \%(n=80)$ \\
by School & \\
\hline Residence & Oklahoma $=67 \%(n=169) ;$ Texas $=30 \%(n=76) ;$ Other $=3 \%(n=7)$ \\
\hline Town & Smaller than 5,000 people $=46 \%(n=116) ; 5,000-10,000=18 \%(n=45) ;$ \\
Size & $11,000-20,000=22 \%(n=55) ; 30,000-50,000=11 \%(n=28) ; 60,000$ or greater $=3 \%(n=8)$ \\
\hline
\end{tabular}

Note. $N=252$. Income is the annual household income. The Business School includes Accounting, Management, Marketing, and Hospitality. Arts and Humanities includes English, Communications, Music, and Native Studies. Arts and Sciences includes Liberal and Applied Science, and Psychology. STEM Sciences include Fish/Wildlife Management, Agriculture, Aviation, Safety, Biology, Nursing, Chemistry, Science, Criminal Justice, and Computer Science.

\section{FINDINGS AND DISCUSSION}

Through fashioning their blog site and reflective essay, students in the ecocompositionoriented course engaged with ecological themes by conducting research, writing digitally, collaborating with classmates in fashioning blogs about sustainability-related 
issues, and thinking critically. Students also linked their interests, backgrounds, majors, and knowledge of sustainability topics to environmental concerns regarding the place they showcased. Moreover, upon completing the assignment, a majority of students identified gains in their sense of personal and social environmental responsibility, as well as in their knowledge of the natural world, and students also reported the blog assignment as being valuable in addressing contemporary problems.

\section{Researching, Writing Digitally, and Collaborating}

In composing a place-based blog and writing digitally, students discussed their personal experiences and any ethnic or tribal connections to their location, researched the site's history, and deliberated with classmates about any controversial issues attached to their spot. Environmental concepts can be complex and complicated to address, yet students utilized their knowledge and research, and collaborated with classmates as compositionrelated strategies to construct their location-related subjects. Often, the general population lacks an understanding of sustainability conversations (McFarlane \& Ogazon, 2011), and at the blog unit's outset, many students, asked to discuss sustainability concepts linked to their place, could provide little input in class. Likewise, the requisite for students to identify local knowledge in participating in ecological conversations (see Marx, 2008) posed an issue for some, who they did not believe they had any such awareness. Yet, even as James Berlin (1996) argues that all language is "interested," and texts are grounded within particular times and spaces (p. 72), the author encouraged students to consider their own experiences; research and interact with sustainability topics without desiring closure; and reject the promises of hierarchicalbased metanarratives evoking paradigms of a pastoral past, uncertain present, and utopic or apocalyptic future (see Killingsworth, 2005). In writing their blogs, students analyzed environmental constructs in both the readings that they selected and that the class covered to determine what might be gained proprietarily by giving any one credence. Moreover, they utilized ecocomposition approaches to explore and shape digital rhetoric related to their place's blog site (see Walker, 2010). Likewise, within the revision process, students collaborated by discussing and reviewing one another's work.

In the study post-survey, as the largest category of any of the blog assignment's academic outcomes, 90 percent of students $(n=227)$ reported that their completion of the blog supported their reading and research skills' growth. As a category in close second, 85 percent $(n=214)$ believed that completing the blog facilitated advancements in their digital writing skills. In smaller numbers, 70 percent $(n=176)$ reported that the collaborative practices they employed during the blog unit were strengthened as a result.

\section{Measuring Digital Writing Outcomes for the Blog Site}

As described in the methodology, raters assessed students' writing outcomes for the blog site. In the following order, raters identified that the students sampled performed highest in the areas of 1) development and clarity, with 80 percent $(n=40)$ of blogs fulfilling the objective, and 2) organization, with 79 percent $(n=40)$ satisfying the criteria. Likewise, the sustainability-themed blog assignment and course's ecocomposition focus also aided most students sampled in fulfilling the blog's other requirements, with 75 
percent $(n=38)$ meeting outcomes for audience and genre expectations, as well as 68 percent $(n=34)$ for diction, style, and voice. While a place-based course theme aids students in completing assignments (Beaufort, 2012), the author's study indicates that when students interact with sustainability themes and ecocomposition designs, they can also produce satisfactory work for various outcomes related to a blog assignment's completion in at least 67 percent $(n=34)$ of cases. See Table 2.

Table 2

Raters' assessment of the student sample's ability to address the blog assignment's various categories

Writing Categories and the Percentage of Papers Associated with Each Category, with "1" Being the Lowest, " 3 " Being Satisfactory, and " 5 " the Highest

\begin{tabular}{lccccc}
\hline & 1 & 2 & 3 & 4 & 5 \\
\hline Organization & $10 \%$ & $11 \%$ & $35 \%$ & $23 \%$ & $21 \%$ \\
\hline Development and Clarity & $11 \%$ & $9 \%$ & $27 \%$ & $28 \%$ & $25 \%$ \\
\hline Diction, Style, and Voice & $15 \%$ & $17 \%$ & $33 \%$ & $20 \%$ & $15 \%$ \\
\hline Audience Requirements & $14 \%$ & $11 \%$ & $46 \%$ & $16 \%$ & $13 \%$ \\
\hline Formatting and Genre Requirements & $13 \%$ & $20 \%$ & $45 \%$ & $12 \%$ & $10 \%$ \\
\hline
\end{tabular}

Note. $N=50$.

\section{Critical Thinking}

In the course post-survey, students answered the following question: "After having encountered and reflected on the concept of sustainability in class, define what 'sustainability' means to you." In addressing this question, many students discussed how their views about sustainability had changed as a result of engaging in the blog assignment and thinking critically about environmental conversations. One male Choctaw student, an aviation major, explained, "I suppose my line of thinking has altered during the course of this semester. I have written about some great places that would devastate not only me, but the surrounding community, if they were to be lost or polluted by human neglect. So, 'sustainability,' in the environmental sense of the word, refers to the ability of the local community to take care what they have around them, so that future generations will be able to enjoy those natural wonders for years to come." As in this example, with their answers, many Native American students, in particular, mentioned the need to consider future generations in making daily choices. Additionally, some students noted the requisite to educate others about conserving the environment. One Choctaw, male, finance major declared, "I feel that sustainability is not a word that is used in many households. I believe that more people need to be educated on being environmentally friendly and what they can do to do their part."

Interestingly, in thinking critically about the environment, students also held different views concerning the world's potential ability to act more sustainably. About a third, being mostly being Native American, warned that unless further sustainable measures were implemented, the planet would suffer. One Choctaw, male, science major explained, "Sustainability to me means endurance. Being told you will fail and standing by your cause any way. I feel very strongly about Oklahoma's water rights, and though it 
has been a long fight, I believe they are worth fighting for; they are just as important as a rainforest facing destruction." Generally, the Native American students remained positive about the potential for change. Comparatively, a fifth of students, mostly Caucasian, felt that it was too late already to make adjustments. One Caucasian, female, education major exclaimed, "How long until we have done too much damage to the earth for us to survive? Sustainability has a grim outlook in my opinion."

Throughout the blog unit, most students reacted with interest to sustainability topics, even if not all grasped their complexities in considering them critically. Yet as time progressed, students discussed sustainability concepts in more complex manners, such as by linking socioeconomic status to people's access to resources. In the post-survey, as an academic outcome upon finishing the blog, 80 percent of students $(n=202)$ believed that the assignment strengthened their critical-thinking skills. Comparably, 47 percent ( $n$ $=118$ ) agreed that completing the blog "improved [their] understanding" of the sustainability topics about which they had read, thought, and written, while 46 percent ( $n=116)$ were neutral. See Table 3 for the larger sustainability definitions that students formulated in their post-survey comments.

Table 3

Sustainability definitions that coders identified in students' post-survey

Being conscious of one's imprint on the planet $(n=14)$ and keeping nature beautiful $(n=2)$ Creating greater sustainable practices $(n=14)$ and going green $(n=4)$

Protecting the natural environment $(n=24)$ and sustaining it $(n=12)$

Keeping something alive or functioning $(n=2)$ or creating balance $(n=4)$

Growing one's food $(n=1)$, recycling $(n=6)$, and collecting trash $(n=1)$

Lowering one's carbon footprint $(n=2)$ and conserving natural resources, including water $(n=$ 6) and gasoline $(n=1)$

Educating others $(n=2)$, working together $(n=6)$, and considering future generations $(n=8)$ Note. $N=252$.

Connecting Sustainability Themes to Students' Interests, Careers, and Communities

After completing the blog assignment, in the post-survey, most students identified gains in their understanding of place-related topics and sense of personal and social environmental responsibility as outcomes. Seventy-five percent $(n=189)$ reported that the assignment "enhanced their knowledge of the natural world," while 80 percent $(n=$ 202) reported that it "improved [their] sense of personal and social responsibility related to the environment." Furthermore, separately, 65 percent of students $(n=164)$ believed that the assignment "promoted [their] educational and personal goals" and "proved useful to addressing real world problems."

In the study, students' backgrounds, majors, and knowledge of sustainability topics impacted their expression of environmental concerns regarding the places they portrayed in their blogs. In their reflective essay and survey responses, many students, who enjoyed sustainability topics, linked them to their identity aspects, including memberships, academic disciplines, and occupations. Additionally, by the end, most had discovered sustainability discussions to be more relevant to their favorite places and 
intended jobs than they had believed. As a related fact, over the next decade, approximately three million STEM majors will graduate, an increase of 33 percent (Gates \& Mirkin, 2012).

Although, at the course's end, most students surveyed reported that they had learned more about environmental concerns and cared more about the world's future than before, not everyone was willing to take personal responsibility for their environmental choices as a result. Unsurprisingly, in a ranking of each state in the Union's "green level" in six categories--carbon footprint, air quality, water quality, hazardous waste management, policy initiatives, and energy consumption--Oklahoma placed 38th (Wingfield \& Marcus, 2007). Likewise, when a study compared college students from Alabama and Hawaii concerning their sustainability knowledge, regard for the present and future, and opinion of whom was responsible for sustainability measures, all reported having the same degree of knowledge and concern for this topic, yet the students in Alabama, another Southern state, like Oklahoma, reported feeling less of a sense of personal accountability for sustainability issues than those from greener states, like Hawaii (Emmanuel \& Adams, 2011). Within the present study, the Native American students explained that it was valuable for them to describe relevant places for themselves and others, such as through a blog assignment, and they also mentioned the importance of both the individual and community in being involved in taking action. One Choctaw, female, English major wrote, "Sustainability means to work together to ensure growth in the community."

\section{Facing the Blog Assignment's Conflicts}

As the blog unit progressed, students engaged with environmental discourses in a continually complex manner. Nonetheless, not everyone liked interacting with sustainability themes and ecocomposition practices (see Orr, 1990). Seven percent of students $(n=18)$ surveyed did not favor the environmentally-based blog assignment and called their interaction with sustainability discourses "boring" and "pointless." Additionally, one student, a Caucasian, female, business major, had mixed feelings about balancing sustainability interests with generating company profits. For Owens (2001), an ecologically-themed curriculum propels students to create a more sustainable society. Still, engaging students in environmental topic discussions may not always produce harmonious outcomes, since achieving sustainability can mean promoting "antigrowth and predevelopment" goals and overturning work conceptions (p. 27-32).

As elements impacting students' involvement with environmental conversations, their past experiences and familiarity with sustainability subjects also influenced their perception of the blog assignment. Some students, who, at first, believed they did not know how to include a sustainability component in their blog, mentioned that they possessed little prior experience with ecological subjects. Having narrow views of sustainability at the outset, these students admitted to feeling nervous about completing the blog's nature-related aspect. For example, while many liked discussing subjects, including water usage and land conservation, via personal pastimes involving swimming, fishing, and hunting (see Johnson-Sheehan, 2007), others described the hardships they encountered in linking larger environmental matters to their own 
experiences via the reflective essay. Comparatively, for Goggin and Waggoner (2005), fully interacting with ecological discourses proved too multifaceted for one course to cover. Yet, because sustainability conceptions are far-flung, students could discuss many concerns. Overall, more state and federally funded universities are including environmental education in the curriculum. However, before students can be expected to be ecologically responsible, they must be familiar with sustainability terms and concepts, including those related to economic, social, and ecological topics (Emmanuel \& Adams, 2011).

\section{Summary of Findings and Analysis}

Regardless of the struggle on some students' part, in Professional and Technical Writing, with including sustainability themes in their blog site, students' completion of the blog and reflective essay led most to improve their research, digital writing, collaborative, and critical-thinking processes. All years, students' knowledge of and interest in sustainability and place increased, and at least 70 percent $(n=176)$ surveyed also reported that their completion of the blog facilitated advancements in each of the areas of research, digital writing, collaboration, and critical thinking, all important course outcomes. Additionally, an effort to reach and retain students by employing ecocomposition practices on the author's part, as the teacher, resulted in students' exploration and growth in their academic, career-related, personal, and larger environmentally oriented goals and experiences, with at least 65 percent $(n=164)$ reporting that their undertaking of the blog aided them in each aforementioned area.

In comparison to the survey, in the blog sites and reflective essays sampled, most students, discussing the class's ecological themes in the reflective essay, also referenced their interaction with sustainability subjects and ecocomposition design as valuable to their completing of the blog, as well as promoting their career-related, personal, and larger objectives. In the reflective essay, 65 percent $(n=64)$ responded positively to integrating sustainability themes into their blog, and the rest did not mention the topic, not being required necessarily to do so. On a related note, students, who portrayed place-based topics positively in the reflection, also performed better on the blog assignment.

Additionally, the blog assignment increased students' awareness and knowledge of environmental conversations and practices, if not always their preference for learning more about or engaging in actions related to them. For "ordinary citizens, sustainability has little or no meaning" (2011, p. 83), and as the blog unit began, some students, belonging to a greater social group, possessed only a limited comprehension of environmental concerns. Nevertheless, most were able to grasp and implement locationrelated discourses into a rather difficult digital writing assignment all on its own, as more than half of students had no previous experience with generating or interacting with a blog. For Native American students, the ability to assume new values while relying on a traditional Native identity can contribute academic and personal success (Demmert, 2001), and in the study, in writing the reflective essay, many students, including Indigenous students, mentioned their assumption of new ideals and practices supportive of both their ethnic backgrounds and sustainability issues. 
Altogether, the study's findings uphold researchers' claims regarding the benefits of offering themed environmental classrooms and ecocomposition practices and point to their valuable effects upon students' writing, research, collaborative, and criticalthinking outcomes, as well as their understanding of and sensitivity toward ecological topics related to their major and places of importance to them. Moreover, the study contributes to the field by providing new knowledge of the effects of a sustainabilityoriented blog assignment and reflective essay and their assessed outcomes upon rural and Native American students at a regional, Southwestern university.

\section{CONCLUSION}

Weisser and Dobrin have asked ecocompositionists to explore the field and critique its beginning forays (2001). Incorporating sustainability themes and place-based design into a course's curriculum can be difficult, especially when faculty do not offer a specific sustainability definition to students, leaving it to them instead, and the latter do not possess a scientific background (McFarlane \& Ogazon, 2011). Yet, on his part, Orr (1991) contends, "All education is environmental education. By what is included or excluded we teach students that they are part of or apart from the natural world" (p. 52). As a recommendation for interested faculty and writing program administrators, offering sustainability components and an ecocomposition design as part of professional and technical writing classes may produce a unified, relevant approach for units involving students' place-related blog production. Specifically, an ecocomposition-based approach to a blog assignment about sustaining an important space may assist students in their research, digital writing, collaborative, and critical-thinking practices, whether they know only a little about environmental topics or are well-versed in them. Likewise, creating environmentally-oriented blogs can link students with concerns in their personal lives and majors and prompt them to reach out to larger audiences.

In this study, after investigating environmental and place-based issues in their blogs, many students discovered that reflecting upon their actions, collaborating with others, and living sustainably involved documenting in writing, including via digital formats, such as the blog, the imprint that one is leaving. In particular, the Native Americans students indicated that they have much to teach other races about preserving the earth in an era confronted by environmental crisis (see Aftandilian, 2011). Indeed, during and after America's Civil Rights era, many Choctaws strengthened their commitment to their historical heritage (Howard \& Levine, 1990). The Choctaws refer to themselves as being "a tribe of artists, professionals, musicians, storytellers, innovators, leaders, athletes, warriors, and caregivers" (Choctaw Nation, 2018). Accordingly, in the study's Professional and Technical Writing class, by generating a blog about a valuable place, Choctaw students were able to implement many of these aforementioned roles in describing their locale with a creative, researched approach as artists, telling a narrative about their relationship to a space as storytellers and writers, and urging others to protect valuable areas for the future as professionals and collaborators, innovators and critical thinkers, and community caregivers. 


\section{STUDY LIMITATIONS AND FUTURE DIRECTIONS}

Concerning the study, some limitations will be discussed, along with a call for further research. Namely, as a larger limitation, the current study was unable to compare students' outcomes upon engaging in a blog assignment containing a sustainability component with a control group, which did not complete this assignment, since no other faculty in the department, besides the author, assign a sustainability component for student blogs. Future studies could address the question of whether offering a sustainability course theme specifically, as opposed to another subject, would improve students' research, writing, collaborative, and critical-thinking outcomes in their fashioning of a blog site for a professional and technical writing class. As a second limitation, the study did not track students longitudinally to ascertain if they would continue to be interested in sustainability topics in the future or chart what steps, if any, students took in beginning or continuing their environmental practices. Future studies could follow students longitudinally to assess these results. As a third limitation, similarly, the study did not follow students to ascertain the results upon them of their having any engagement with their blog's audience. A continuing study could determine how students and their audiences interacted in forming potential communities. As a last limitation, while this study's participants represented mostly Caucasians and Native Americans, with the latter living outside reservations, further studies could focus on the engagement of a blog assignment with a sustainability component by other racial student minorities, as well as other Native American tribal students or those on reservations. Finally, to compare results amongst institutional types and geographical areas, subsequent scholars might conduct studies of ecocomposition practices and a sustainability curriculum involving student blogs in professional and technical writing courses at both research universities and community colleges, including in geographically diverse locations.

\section{REFERENCES}

Aftandilian, D. (2011). What other Americans can and cannot learn from Native American environmental ethics. Worldviews, 15, 219-246.

Alaimo, S. (2010). Sustainable this, sustainable that: New materialisms, posthumanism, and unknown futures. PMLA, 127(3), 558-564.

Bahr, A. (2015). People of place, ethics of Earth: Indigenous nations, interfaith dialogue, and environmental sustainability. Journal of Ecumenical Studies, 50(1), 6676.

Berlin, J. (1996). Rhetorics, poetics, and cultures: Refiguring college English studies. Urbana: NCTE.

Beaufort, A. (2012). College writing and beyond: Five years later. Composition Forum, 26.

Bovill, C., Bulley, C., \& Morss, K. (2011). Engaging and empowering first-year students through curriculum design. Teaching in Higher Education, 16(2), 197-209. 
Brokenleg, M. (1990). The Circle of Courage and Meeting the Needs of Youth Abridged Version.

Brown, S. (1999). Composing the eco wars: Toward a literacy of resistance. JAC, 19(2), 215-239.

Choctaw Nation. (2018). History and Culture. Retrieved 1, Mar. 2018 from www.choctawnation.com.

Conley, E., \& Bryan, V. (2009). Elements needed to support social, ecological, and economic sustainability on a global basis by educational practitioners for Native American Indigenous people. International Forum of Teaching and Studies, 5(2), 2226.

Cresswell, J. (2012). Qualitative Inquiry and Research Design. Sage.

Cresswell, J., \& Miller, D. (2000). Determining validity in qualitative inquiry. Theory into Practice, 39(3), 124-130. https://people.ucsc.edu/ ktellez/Creswell_validity2000.pdf.

Curnow, P. (2011). Indigenous skies. Australian Science, 32(8), 22-25.

Dewey, J. (1915). Democracy and education. New York: Free P.

Demmert, W. (2001). Improving academic performance among Native American students: A review of the literature. Charleston, WV: ERIC.

Dippel, C. (2014). Forced coexistence and economic development: Evidence from Native American reservations. Econometrica, 82(6), 1-36.

Dobrin, S., \& C. Weisser. (2002a). Breaking ground in ecocomposition: Exploring relationships between discourse and environment. College English, 64(5), 566-589.

---. (2002b). Natural discourse: Toward ecocomposition. SUNY P.

Emmanuel, R., \& Adams, J. (2011). College students' perceptions of campus sustainability. International Journal of Sustainability in Higher Education, 12(1), 7992.

Fitts, K. (2005). Ideology, life practices, and pop culture: So why is this called writing class? Journal of General Education, 54(2), 90-105.

Friedman, S. (2013). This way for vampires: Teaching first-year composition in 'challenging times.' Teaching and Learning, 6(1), 77-84.

Gaard, G. (2001). Ecofeminism and ecocomposition: Pedagogies, perspectives, and intersections. In C. Weisser \& S. Dobrin (Eds.). Ecomposition: Theoretical and pedagogical approaches (pp. 163-178). Albany: SUNY P.

Garrett, N., Bridgewater, M., \& Feinstein, B. (2017). How student performance in firstyear composition predicts retention and overall student success. In T. Ruecker (Ed.), Retention, Persistence, and Writing Programs (pp. 93-113). Utah SUP. 
Gates, J., \& Mirkin, C. (2012). Encouraging STEM students is in the national interest. Chronicle for Higher Education.

Goggin, P., \& Waggoner, Z. (2005). Sustainable development: Thinking globally and acting locally in the writing classroom. Composition Studies, 33(2), 45-67.

Graff, G., \& Hoberek, A. (1999). Hiding It from the Kids (With Apologies to Simon and Garfunkel). College English, 62, 242-254.

Guillory, R. (2009). American Indian/Alaska Native College Student Retention Strategies. Journal of Developmental Education, 33(2), 14-40.

Guillory, R., \& Wolverton, M. (2008). It's about family: Native American student persistence in higher education. Journal of Higher Education, 79(1), 58-87.

Hain-Jamall, D. (2013). Native-American \& Euro-American cultures: A comparative look at the intersection between language and worldview. Multicultural Education, 1319.

Hankes, J. (1998). Native American pedagogy and cognitively based mathematics instruction. Garland, New York.

Harkin, M., \& Lewis, D., eds. (2007). Native Americans and the environment: Perspectives on the ecological Indian. Lincoln: University of Nebraska P.

Heiman, J. (2014). Odd topics and open minds: Implementing critical thinking in interdisciplinary, thematic writing courses. Pedagogy, 14(1), 107-135. Retrieved 15, Mar. 2018 from doi:10.1215/15314200-2348929.

Hothem, T. (2009). Suburban studies and college writing: Applying ecocomposition. Pedagogy, 9/1, 197-212.

House, V. (2016). Keeping writing weird: A call for eco-administration and engaged writing programs. Community Literacy Journal, 11(1), 54-63.

Howard, J., \& Levine, V. (1990). Choctaw Music and Dance. Norman: U of OK P.

Johnson-Sheehan, R. (2007). Composing nature. The Writing Instructor.

Killingsworth, J. (2005). From Environmental Rhetoric to Ecocomposition and Ecopoetics: Finding a Place for Professional Communication. Technical Communication Quarterly, 14(4), 359-373.

Lipka, J. (2002). Schooling for self-determination: Research on the effects of including Native language and culture in the schools. ERIC. Retrieved 1, Mar. 2018 from www.uaf.edu/mcc/award-recognition-and- oth/schooling-for-self-determination.pdf.

Long, M. (2001). Education and environmental literacy: Reflections on teaching ecocomposition in Keene State College's environmental house. In C. Weisser \& S. 
Dobrin (Eds.), Ecocomposition: Theoretical and pedagogical approaches (pp. 131145). SUNY P.

Marx, S. (2008, Aug. 3). Think global, write local: Sustainability and English composition. Paper presented at UC/CSU/CCC Sustainability Conference. Cal Poly. San Luis Obispo, CA.

McFarlane, D., \& Ogazon, A. (2011). The challenges of sustainability education. Journal of Multidisciplinary Research, 3(3), 81-107.

McKnight, M. (2001). Reviewed work: Ecocomposition: Theoretical and pedagogical approaches by Christian R. Weisser and Sidney I. Dobrin. JAC, 21(4), 927-933.

Merriam, S. (1985). "The Case Study in Educational Research: A Review of Selected Literature." Journal of Educational Thought, 19(3), 204-17, www.jstor.org/stable/23768608.

Merrill-Ingram, A. (2001). Service learning and ecocomposition: Developing sustainable practices through inter- and extradisciplinarity. In C. Weisser \& S. Dobrin (Eds.), Ecocomposition: Theoretical and pedagogical approaches (pp. 209-233). SUNY P.

Monsma, B. (2001). Writing home: Composition, campus ecology, and webbed environments. In C. Weisser \& S. Dobrin (Eds.), Ecocomposition: Theoretical and pedagogical approaches (pp. 281-290). SUNY P.

Mosholder, R., et al. (2016). Promoting Native American college student recruitment and retention in higher education. Multicultural Education, 27-36.

Munroe, E., et al. (2013). Decolonizing indigenous education in the 21 st century. McGills Journal of Education, 48(2), 317-337.

Orr, D. (1990). The liberal arts, the campus, and the biosphere. Harvard Educational Review, 60/2, 205-216.

---. (1991). What is education for? Six myths about the foundations of modern education and six new principles to replace them. The Learning Revolution, 52.

Owens, D. (2001). Composition and sustainability: Teaching for a threatened generation. Urbana: NCTE.

Pewewardy, C., \& Cahape-Hammer, P. (2003). Culturally Responsive Teaching for American Indian Students. ERIC Digests.

Porter, J. (2012). Land and spirit. Santa Barbara: Praeger.

Shotton, H.; Oosahwe, E.; \& Cintron, R. (2007). Stories of success: Experiences of American Indian students in peer mentoring retention programs. Review of Higher Education, 31(1), 81-108. 
Sianturi, M.; Chiang, C.; \& Au Hurit, M. (2018). Impact of a place-based education curriculum on Indigenous Teacher and Students. International Journal of Instruction, 11(1), 311-328.

Smith, G. A., \& Sobel, D. (2010). Place- and community-based education in school. New York: Routledge.

Sobel, D. (2004). Place-based education. Great Barrington, MA: Orion P.

Sommers, N., \& Saltz, L. (2004). The novice as expert: Writing the freshmen year. College Composition and Communication, 56(1), 124-149.

Stake, R. (1995). The art of case study research. Thousand Oaks: Sage.

Strand, Kerry, et al. Community-based Research and Higher Education: Principles and Practices. Jossey-Bass, 2003.

Stephens, J., et al. Higher education as a change agent for sustainability in different cultures and contexts. International Journal of Sustainability, 9(3), 317-338.

Szostak, R. (2003). "Comprehensive" curricular reform: Providing students with a map of the scholarly enterprise. Journal of General Education, 52(1), 27-49.

Sumner, D. (2001). Don't forget to argue: Problems, possibilities, and ecocomposition. In C. Weisser \& S. Dobrin (Eds.), Ecomposition: Theoretical and pedagogical approaches (pp. 265-280). SUNY P.

Tuhiwai-Smith, L. (2012). Decolonizing methodologies: Research and Indigenous peoples. London: Zed Books. University Factbook, 2018. (2018).

Walker, P. (2010). (Un)earthing a vocabulary of values: A discourse analysis for ecocomposition. Composition Studies, 38(1), 69-87.

Weed, A. (2003). Critical transcendence in composition and literature. Journal of General Education, 52(1), 14-19.

Weisser, C., \& Dobrin, S. (2001). Breaking New Ground in Ecocomposition: An introduction. C. Weisser \& S. Dobrin (Eds.), Ecocomposition: Theoretical and pedagogical approaches (pp. 1-10). SUNY P.

Yazzie, T. (2000). Holding a mirror to 'wide shut': The role of Native cultures and languages in the education of education of American Indian students. ERIC.

Yin, R. (2009). Case Study Research: Design and Methods. Thousand Oaks: Sage.

Wingfield, B., \& Marcus, M. (2007). America's Greenest States. Forbes. 